\title{
Visibility of Chinese ad hoc medical interpreters through text ownership: A case study
}

\author{
Wei Zhang \\ Beijing Foreign Studies University \\ zhangwei030507@bfsu.edu.cn \\ https://orcid.org/0000-0001-7640-5790 \\ Cui Xu \\ Beijing Institute of Technology \\ xcui0414@126.com \\ https://orcid.org/0000-0002-8373-3749
}

\begin{abstract}
Professional interpreters' visibility in the European context has been widely discussed in the field of community interpreting, but the visibility of untrained ad hoc interpreters in nonEuropean contexts such as China has received little academic attention. By adopting the concept of "text ownership" proposed by Angelelli (2004a), this study examines Chinese ad hoc interpreters' manifestations of visibility in an authentic medical setting. Based on field observations, audio recordings and interviews, the study reports on four types of visibility demonstrated by ad hoc interpreters: (a) replacing the interlocutor; (b) expressing affect towards a patient; (c) exploring answers; and (d) brokering comprehension. Other forms of visibility are also identified, such as omissions of doctors' or patients' remarks and small talk between doctor and interpreter. Interpreters' deeply held views on social factors as well as the institutional and social norms they have been exposed to are believed to influence their manipulation of medical discourses. This study concludes that in a context where professional medical interpreting services are unavailable, ad hoc interpreters may act as linguistic facilitators by taking on various roles that go beyond mere interpreting. However, their excessive visibility may give rise to potential clinical risks, especially when direct doctorpatient communication is compromised. Attention is drawn to the importance of proper training as well as to the need for the professionalization of medical interpreting in China.
\end{abstract}

Key words: ad hoc interpreters; text ownership; medical setting; visibility; habitus 
Zhang, W., \& Xu, C. (2021). Visibility of Chinese ad hoc medical interpreters through text ownership: A case study. Linguistica Antverpiensia, New Series: Themes in Translation Studies, 20, 136-158.

\section{Introduction}

This study investigates the visible role performances of a special type of medical interpreter, namely untrained ad hoc interpreters (Bührig \& Meyer, 2004), or lay interpreters (Hsieh, 2006; Ticca, 2017), in the Chinese medical context. The overarching goal is to observe the ways in which ad hoc interpreters - a role which is often assumed by a patient's friend, a family member or bilingual hospital staff - manifest their visibility by "going beyond mere interpreting" (Baraldi \& Gavioli, 2017, p. 84) and creating their own texts (Angelelli, 2004a). Moreover, the study sought to record the ways in which they may help overcome language barriers and facilitate medical treatment when professional interpreting is not available, as is often the case in the Chinese medical context.

The use of ad hoc or untrained non-professional medical interpreters (Hsieh, 2006) is not uncommon, even in countries where professional medical interpreting is available (e.g., Bischoff \& Hudelson, 2010; Gerrish et al., 2004; Herrera, 2008; Lee et al., 2006). Much of the previous literature, however, is devoted to the role expectations and role performances of professional interpreters, together with the two contrasting positions in community interpreting. The first position is prescriptive, which is often stipulated in guidance books (Tebble, 1998) or professional codes of ethics (California Healthcare Interpreters Association [CHIA], 2002; Massachusetts Medical Interpreters Association [MMIA], 1995); it requires interpreters merely to translate and maintain impartiality and neutrality in the process. A number of metaphoric labels, such as "a conduit" (Reddy, 1979), "a translation machine" (Knapp-Potthoff \& Knapp, 1986) and a "language-switching operator" (Angelelli, 2004a) have been proposed to echo these codes of ethics. This kind of conduit model "conceptualizes interpreters as robots", emphasizing interpreters' invisible, non-thinking and non-feeling role performances (Hsieh, 2008, p. 1367). The second position, which has been gaining momentum in recent decades, is that medical interpreters are often found to "go beyond mere interpreting" (Baraldi \& Gavioli, 2017, p. 84) since they are co-participants and co-constructors in contextualized medical consultations where the power relations between doctors and patients are always unequal (Nimmon \& Stenfors-Hayes, 2016). Therefore, instead of being an invisible conduit, interpreters often adopt the role of a "cultural broker" (Crezee \& Ng, 2016; Larrison et al., 2010), a "patient advocate" (Kaufert \& Putsch, 1997; Valero-Garcés, 2005), a "mediator" (Wadensjö, 1998), a "gatekeeper" (Davidson, 2001), a "co-interlocutor" (Ren, 2010), a "codiagnostician" (Davidson, 2000), or even an "interventionalist" (Clifford, 2005) when ethically delicate situations occur to facilitate intercultural communication in medical settings.

This "tug-of-war" between the normative prescriptions advocated by the first position and the various mediation roles actually taken by medical interpreters continues, especially in the context of some immigrant countries where community interpreting services are considered to be a basic right for immigrants (including refugees). We focus, however, on a distinct context, that is, the Chinese medical context, where professional interpreting services are unavailable because of the less complex composition of immigrants in China and the bilingual status of 
Zhang, W., \& Xu, C. (2021). Visibility of Chinese ad hoc medical interpreters through text ownership: A case study. Linguistica Antverpiensia, New Series: Themes in Translation Studies, 20, 136-158.

medical practitioners (and sometimes, patients). In 2017, the authors conducted 30 informal telephone interviews. We found that, among the 30 public third-class A-level hospitals in Beijing we investigated, none provided professional interpreting services for foreign patients for the reasons stated above. Zhan and Yan (2013) reported only one hospital in Guangzhou that offered such a service. In most cases, doctors communicate directly with patients in English or they may recruit bilingual hospital staff members. Alternatively, friends or family members who accompany the patient may act as ad hoc interpreters to help facilitate medical consultations (see also Su, 2009). Such temporarily recruited, untrained medical interpreters (i.e., ad hoc interpreters) may demonstrate different role performances from professional and/or trained practitioners. This is due to their lack of proper training, their lack of recognition of professional codes of ethics for medical interpreters and the dual or even multiple roles they assume besides being an ad hoc interpreter. It is in such a context that we are intrigued to examine the actual role performances of untrained ad hoc interpreters in authentic medical settings.

To explore their actual role performances and also to enrich the literature dominated by studies on professional interpreters in the European context, this study focuses on ad hoc interpreters in an authentic medical setting in China. It attempts to reveal their manifestations of visibility, that is, any role performances beyond being a language-switching operator (Angelelli, 2004a), through the concept of "text ownership" (Angelelli, 2004a). The main assumption is that interpreters, whether ad hoc or not, do not simply translate the speech. As an essential part of triadic (doctor-interpreter-patient) consultations (Angelelli, 2004b), they constantly help to construct and re-construct the medical discourses and make themselves visible to both parties.

This research explores three questions: (a) What are the specific manifestations of ad hoc interpreters' visibility as examined from the perspective of text ownership? (b) Do ad hoc interpreters with different identities (other social roles aside from being an ad hoc interpreter) reveal their visibility in the same or similar ways? If yes, what are these ways? If no, what are the differences? and (c) Why do they manifest their visibility in such ways?

\section{Analytical framework}

The concept of text ownership was first proposed by Angelelli (2004a) to describe the various roles played by professional medical interpreters that go beyond mere translating. However, she did not explain the theoretical foundations of her classification of text ownership. We find that the (in)visible roles played by interpreters can be related to the three distinct roles explained by Goffman (1981) in his description of the "production format of an utterance": namely, "animator, author and principal" (p. 145). In Goffman's (1981) view, an author of the words being heard refers to "someone who has selected the sentiments that are being expressed and the words in which they are encoded" (p. 144). An author, therefore, holds the power regarding the selection of words and the creation of utterances. In contrast, an 
Zhang, W., \& Xu, C. (2021). Visibility of Chinese ad hoc medical interpreters through text ownership: A case study. Linguistica Antverpiensia, New Series: Themes in Translation Studies, 20, 136-158.

animator is like "the sounding box in use, albeit in some actual cases he can share this physical function with a loudspeaker system or a telephone. In short, he is the talking machine, a body engaged in acoustic activity" or even "an individual active in the role of utterance production" (p. 144). In this sense, an animator, although acting as a speaker, is invisible, and has to reproduce the words and sentiments of the author without taking any personal stance. A principal is "someone whose position is established by the words that are spoken, someone whose beliefs have been told, someone who is committed to what the words say" (p. 144). When a person assumes the role of a speaker, they may take on the role of an animator, an author, a principal, or all three roles.

In the field of community interpreting, Wadensjö (1998) first introduced and adapted Goffman's (1981) production format of an utterance to interpreter-mediated communicative events (i.e., medical interpreting). On the basis of Goffman's (1981) three key concepts which focus on the speaking side (i.e., the role of a speaker), Wadensjö (1998) put forward a "reception format of an utterance" to indicate the triadic interaction in interpreter-mediated doctor-patient consultations. She proposed three concepts to describe the interpreter's roles - a reporter, a responder and a recapitulator - which are closely related to the three concepts mentioned above. A reporter's role corresponds to that of an animator, which is invisible, but it is "seldom explicitly given to a person addressed (except in highly formalized situations, such as the say-after-me language lesson)" (Wadensjö, 1998, p. 92). Adopting the role of responder indicates that the person being addressed "would anticipate/be expected either to take discourse further by introducing content of their own, or at least - by backchannelling, gazing, etc. - to make salient that they accept being so addressed" (p. 92). The recapitulator role requires a person to be both an animator and an author, but not a principal, whose role is usually taken by the original speaker.

The presentation of the reception format, along with Goffman's production format, can be used to indicate the triadic interaction in interpreter-mediated doctor-patient consultations. On the basis of these concepts, Wadensjö (1998) further classified eight types of renditions, that is, "reformulations of prior 'original' utterances" (p. 106), to describe the different roles played by interpreters which go beyond mere translating in authentic encounters. This classification of renditions overlaps with the notion of text ownership proposed later by Angelelli (2004a), which simply means that "the interpreter owns the lines he produces, authors the text. It is not given to them" (C.V. Angelelli, personal communication, February 6, 2017). Angelelli (2004a) argued that "an ICE [interpreted communicative event] might have only original messages transmitted by the two parties, a combination of original messages and interpreter-owned messages, or interpreter-owned messages only" (p. 76). By examining interpreters' "amount of involvement in creating text ownership" (p. 76), we can see how visible they are in shaping and reshaping the communicative event.

To better illustrate the intensity of interpreters' visibility, Angelelli (2004a) devised a visibility continuum based on interpreters' claim of text ownership. This continuum ranges from merely controlling turn-taking flows to replacing the interlocutor, the impact of which ranges from 
Zhang, W., \& Xu, C. (2021). Visibility of Chinese ad hoc medical interpreters through text ownership: A case study. Linguistica Antverpiensia, New Series: Themes in Translation Studies, 20, 136-158.

inconsequential to highly consequential. She broadly categorized interpreters' strategies for engaging in text ownership into two types: partial text ownership and total text ownership. As the names indicate, partial text ownership refers to "a combination of original messages and interpreter-owned messages", whereas total text ownership refers to "interpreter-owned messages only" (p. 78). In the former case, the interpreter is a co-owner of the texts in that they not only translate the talks, but also help co-construct the discourse as an essential coparticipant. In the latter case, the interpreter becomes the total owner of the texts, often illustrated through the act of replacing the monolingual interlocutor - which is, more often than not, regarded as highly consequential and extremely unfavourable in professional codes of ethics.

The notion of text ownership has not received adequate academic attention, despite its strong explanatory power in accounting for interpreters' agency. One representative study by Zhan and Zeng (2017) used text ownership as a theoretical framework to deconstruct medical interpreters' invisibility in the Chinese medical context. Their study provided sound evidence of the applicability of text ownership in describing medical interpreters' visible role performances. Another study by Ren (2010), however, saw interpreters' claims of text ownership only as a partial representation of their visibility consciousness; but this view, in our view, underestimates the explanatory power of text ownership. In this study, we attempt to describe interpreters' visible role performances based on Angelelli's (2004a) visibility continuum of text-ownership strategies by focusing on non-professional interpreters temporarily recruited for medical consultations. By so doing, we hope to demonstrate how ad hoc interpreters are actively involved in shaping and reshaping medical discourses, and may also help facilitate medical consultations when professional interpreting is unavailable in the Chinese medical context.

\section{Methodology}

Following the research tradition of ethnomethodology and discourse analysis (e.g., Angelelli, 2004a, 2004b; Ticca, 2017; Wadensjö, 1998), the data analyzed in this study consisted of naturally occurring medical interviews that were audio-recorded in an authentic medical setting in Beijing. The recordings were carried out from November to December 2016. The participants included a male orthopedist from the Department of Traumatic Orthopedics; three patients from Mozambique, Canada and the United Kingdom, respectively; the patients' bilingual colleagues or friends (referred to as "colleague interpreters"), and two bilingual resident doctors already present in the medical setting (referred to as "hospital-based interpreters"). These non-professional bilinguals with heterogeneous (social) identities were later recruited as ad hoc interpreters to facilitate doctor-patient consultations.

Before the data-collection, we obtained consent from all the parties to record their conversations and observe their interactions as bystanders. The recordings were done using a portable recorder. Transcriptions were made following (and adapting) the transcription rules 
Zhang, W., \& Xu, C. (2021). Visibility of Chinese ad hoc medical interpreters through text ownership: A case study. Linguistica Antverpiensia, New Series: Themes in Translation Studies, 20, 136-158.

elaborated in Wadensjö (1998) (see Appendix). To preserve anonymity, in all the transcribed excerpts containing personal names, the names were abbreviated using a single letter together with the "*" symbol, e.g., C*.

In addition to audio recordings, we also carried out field observations and interviews to enrich our data. For the data analysis, we used mainly content analysis, following previous scholarship (e.g., Angelelli, 2004a; Hsieh, 2007). Details regarding the three interpreter-mediated medical interviews and the actual role performances of the ad hoc interpreters are presented in the Findings section.

\section{Findings}

Table 1 presents a summary of the three interpreter-mediated medical interviews. As shown in this table, the identities of the ad hoc interpreters in the three interactions were heterogeneous, and aside from taking on the role of interpreter, they also had different social roles, such as company staff (interpreter 1 ), college student (interpreter 2), and hospital staff (interpreter 3). None of them had undergone any proper training in medical interpreting, and two of them even had a relatively low level of English proficiency. They managed to make themselves understood when translating simple content, but they often struggled and on occasion even sought help from the bilingual doctor when complex topics were dealt with or questions were asked. In Hsieh's (2006) categorization, they would fall into the category of chance, untrained interpreters. Given their distinct social roles, identities and levels of English proficiency, as well as the genetically distinct nature of Chinese and English as source and target languages, their role performances might be expected to differ.

Table 1. Summary overview of the recorded medical interviews

\begin{tabular}{|l|l|l|l|l|l|l|}
\hline Code & $\begin{array}{l}\text { Duration } \\
(\mathbf{m i n} / \mathbf{s})\end{array}$ & Doctor & Patient & Interpreter & Complaint & Total turns \\
\hline 1 & $30^{\prime \prime} 00^{\prime}$ & $\begin{array}{l}\text { Orthopedist } \\
\text { male }\end{array}$ & $\begin{array}{l}\text { Mozambique } \\
\text { male }\end{array}$ & $\begin{array}{l}\text { American } \\
\text { Male }\end{array}$ & $\begin{array}{l}\text { Lower } \\
\text { backache }\end{array}$ & 477 \\
\hline 2 & $20^{\prime \prime} 00^{\prime}$ & $\begin{array}{l}\text { Orthopedist } \\
\text { male }\end{array}$ & $\begin{array}{l}\text { Canada } \\
\text { female }\end{array}$ & $\begin{array}{l}\text { Chinese } \\
\text { Female }\end{array}$ & Ankle pain & 310 \\
\hline 3 & $24^{\prime \prime} 36^{\prime}$ & $\begin{array}{l}\text { Orthopedist } \\
\text { male }\end{array}$ & $\begin{array}{l}\text { United Kingdom } \\
\text { female }\end{array}$ & $\begin{array}{l}\text { Chinese } \\
\text { Female }\end{array}$ & Wrist pain & 276 \\
\hline
\end{tabular}

On the basis of field observations, audio recordings and interviews with healthcare providers, we identified four types of "visibility manifestation" that were demonstrated by the ad hoc interpreters under investigation: (a) replacing the interlocutor; (b) expressing affect towards patient; (c) exploring answers as a co-diagnostician; and (d) brokering comprehension. We also observed other forms of visibility manifestation, such as interpreters' omissions of remarks made by primary interlocutors (doctor and patient), and side conversations between doctor 
Zhang, W., \& Xu, C. (2021). Visibility of Chinese ad hoc medical interpreters through text ownership: A case study. Linguistica Antverpiensia, New Series: Themes in Translation Studies, 20, 136-158.

and interpreter(s), but these cannot be readily explained using text ownership.

\subsection{Macro-analysis - distribution of partial and total text ownership}

As explained in section 2, in many cases, medical interpreters are not merely languageswitching operators (Angelelli, 2004a) or, as Goffman (1981) put it, animators. More often than not, they are active co-participants engaging in the dyadic interaction between doctor and patient. Depending on the amount of their involvement according to their claim of either partial or total text ownership, interpreters reveal their visibility to varying degrees (see Table 2).

Overall, in all three cases we studied, the ad hoc interpreters demonstrated a high degree of visibility, as attested to by the proportions of their claim of total text ownership. On the basis of Angelelli's (2004a) visibility continuum, such highly visible role performances are also highly consequential. In the following sections, we explore in detail the specific manifestations of text ownership claimed by the ad hoc interpreters who participated in our study.

Table 2. Distribution of partial and total text ownership (TO)

\begin{tabular}{|l|l|l|l|l|}
\hline & \multicolumn{1}{|c|}{ Case 1 } & \multicolumn{1}{|c|}{ Case 2 } & \multicolumn{1}{c|}{ Case 3 } & \multicolumn{1}{c|}{ Total } \\
\hline Proportion of lines with partial TO & $1.9 \%$ & $1.0 \%$ & $0.4 \%$ & $2.9 \%$ \\
\hline Proportion of lines with total TO & $6.5 \%$ & $3.5 \%$ & $5.1 \%$ & $15.1 \%$ \\
\hline Proportion of lines with partial and total TO & $9.4 \%$ & $4.5 \%$ & $5.5 \%$ & $18.0 \%$ \\
\hline Duration (min/s) & $30^{\prime \prime} 00^{\prime}$ & $20^{\prime \prime} 00^{\prime}$ & $24^{\prime \prime} 36^{\prime}$ & $74^{\prime \prime} 36^{\prime}$ \\
\hline
\end{tabular}

\subsection{Micro-analysis - four manifestations of text ownership}

\subsubsection{Replacing the interlocutor}

According to Angelelli's (2004a) visibility continuum of text ownership, replacing the interlocutor is considered to be the most visible and consequential role performance. In this study, this type of role performance was fairly common in the question-answer session initiated by the doctor, especially when the patient could speak only very limited English, as was the case in extract 1 . The interpreter's strong agency to replace the primary interlocutor is highly discouraged in interpreting ideologies: as Roy (2000) stated, "interpreters are not supposed to answer direct questions; rather they should pass on the question to allow the primary speaker to answer" (p. 10). Extract 1, however, offers counter-evidence in that the colleague interpreter frequently substituted for the Mozambican patient in answering the doctor's questions (underline), thus becoming the patient's spokesperson.

As evidenced in extract 1, in the initial phase of the enquiry process, the doctor targeted his question towards the patient, as indicated by his use of direct referencing ("you" in turn 1) and his gaze towards the patient. At first, the colleague interpreter attempted to answer the question directly (see the beginning of turn 2), but then realized that perhaps it was more 
Zhang, W., \& Xu, C. (2021). Visibility of Chinese ad hoc medical interpreters through text ownership: A case study. Linguistica Antverpiensia, New Series: Themes in Translation Studies, 20, 136-158.

appropriate to pass on the doctor's question to the patient. But instead of translating the doctor's question word for word ("What's wrong with you?") like a reporter (Wadensjö, 1998), he rephrased the sentence to elicit a more detailed description of the patient's complaints. The Mozambican patient, constrained by his limited English proficiency, resorted to body language by pointing to his lower back to indicate the location of his pain. After learning that the patient could not speak much due to the acute pain, the interpreter, starting from turn 4, decided to communicate with the doctor on behalf of the patient. This was also acknowledged by the doctor, because he changed the direct referencing "you" (turn 1) to the indirect referencing "he" (turn 7). As a result, the patient was no longer an active participant in this triadic interaction but instead became the subject under discussion. In this case, the interpreter claimed total text ownership, acknowledged and authorized by the doctor, and became the full author (Goffman, 1981) of the medical discourse.

Extract 1

1. Doctor: 你怎么了? ((looking at the patient))

What's wrong with you ${ }^{1}$

2. Interpreter: 他是这, 㕪, ((turning to the patient)) C* maybe you can tell him exactly. It's ... He is, er,

3. Patient: Here ((points to his lower back))

4. Interpreter: 特别疼.

Very painful.

5. Doctor: 啊, 特别疼啊.

Ah, very painful.

6. Interpreter: 对, 从昨天开始.

Yes, starting from yesterday.

7. Doctor: 从昨天开始,啊.他这个受过伤吗?

Starting from yesterday, ah ok. Did he get injured?

8. Interpreter: 没有明显的伤. 他坐过很长时间的飞机 ... 大概有三，三周以前他在玩足球的时候，他觉 得是那个时候开始, 对.

There's no obvious injury. He'd been on a plane for a long time. About three, three weeks ago when he was playing football, he started feeling (the pain), from then, yeah.

9. Doctor: 他什么时候坐的飞机?

When did he take the plane?

10. Interpreter: 昨天.

Yesterday.

11. Doctor: 昨天哈.

OK, yesterday.

12. Interpreter: 昨天到的.

He arrived yesterday. 
Zhang, W., \& Xu, C. (2021). Visibility of Chinese ad hoc medical interpreters through text ownership: A case study. Linguistica Antverpiensia, New Series: Themes in Translation Studies, 20, 136-158.

Presenting a different pattern from colleague interpreters in "replacing the interlocutor", hospital-based interpreters (i.e., bilingual hospital staffs) seldom replaced the patient by answering the doctor's question directly. Rather, they would translate the doctor's question to the patient only when necessary. This finding is very different from those of previous studies (Angelelli, 2004a; Prince, 1986; Zhan \& Zeng, 2017) that have investigated the role performances of hospital-based professional interpreters. Those studies reported that an asymmetrically large proportion of questions communicated to the patient was answered directly by the interpreter instead of being translated to the patient. This may be attributed to the distinct identities of the interpreters under discussion and the related different check-up procedures patients need to go through. Specifically, previous studies investigated institutionbased professional interpreters whose daily routine was to meet the patient before the doctor did and to elicit basic information about the patient's complaints. Doing so enabled them to help "gatekeep" information and expedite medical check-ups when time restrictions were imposed. In contrast, our study focused on hospital staff (specifically, resident doctors) as ad hoc interpreters, which eventually gave rise to the different check-up procedures that patients have to go though.

\subsubsection{Expressing affect towards patients}

Expressing affect is defined as the interpreter's expression of advocacy or support for the patient in the interests of their holistic well-being. In such cases, the interpreter assumes the role of patient advocate as they "actively support change in the interest of patient health and well-being" (CHIA, 2002, p. 45). Angelelli (2004a) summarized a number of behaviours that illustrate the interpreter's role as patient advocate, such as offering additional advice and providing more information than expected. In this study, we also identified cases where the ad hoc interpreters showed solidarity (Zhan \& Zeng, 2017) or emotional support (Hsieh \& Hong, 2010) towards the patient, as illustrated in extract 2.

Extract 2

242. Boyfriend: Regarding the plaster cast, does she have to book an appointment to have it taken off, or for herself?

243. Interpreter 2: 需要人照顾吗?

Does she need someone to take care of her?

244. Doctor: 我觉得她自己就可以,不需要.

I think she can do it by herself, so there's no need for that.

245. Interpreter 2: She can take care of herself because his right hand is ...

246. Boyfriend: Yeah ok, brilliant, we don't need to book another appointment for that.

247. Interpreter 2: Yes, but he need to rest, he can't hold something, anything. He need to get his hand on his, er ...

248. Interpreter 1: neck?

249. Interpreter 2: Yes. 
Zhang, W., \& Xu, C. (2021). Visibility of Chinese ad hoc medical interpreters through text ownership: A case study. Linguistica Antverpiensia, New Series: Themes in Translation Studies, 20, 136-158.

258. Interpreter 2: ((turning to the patient)) Hand, er, much more pain, you should come back at once.

259. Patient: OK

In this case, an English patient suffering from wrist pain was accompanied by her boyfriend to the hospital for a bone fracture check-up. After the patient was confirmed to have a bone fracture, her boyfriend took the initiative to get more details regarding her treatment (turns 240 to 246). Once the boyfriend had obtained the information he was seeking, interpreter 2 contributed her own lines by offering additional advice to the patient (turn 247), although her suggestion was not verbally acknowledged by the patient or the patient's boyfriend. Then, after some non-serious small talk (turns 251 to 257), interpreter 2 reminded the patient again that a re-examination would be necessary if the condition did not improve after that (turn 258); this time, the comment was acknowledged verbally by the patient (turn 259). All the underlined turns demonstrate the interpreter's agency to create her own texts in order to show support for the patient. In a subsequent interview, the interpreter explained that the reason she contributed her own lines by offering additional advice is that she believes that her professional identity as a resident doctor outweighs her identity as an ad hoc interpreter. She therefore regarded it as her duty to express humanistic care towards the patient, whose rapid recovery was what she wished for.

\subsubsection{Exploring answers}

Exploring answers is expressed through the interpreter's role as a co-diagnostician in two ways: the interpreter either expands the question the doctor proposes to the patient (Bolden, 2000) or initiates their own turns to facilitate a better understanding of a patient's complaints or medical history. However, somewhat differently from the co-diagnostician role of interpreters reported in the previous literature (e.g., Davidson, 2000, 2001), where professional hospitalbased interpreters often "gatekeep" information to expedite interviews due to strict time restrictions, this research focused on ad hoc interpreters working temporarily in the Chinese medical context, where time limits are generally determined by the doctor. Given the different hospital rules for medical consultations in China and in other countries, interpreters working in Beijing-based hospitals may "co-diagnose" to elicit as much information as possible for the sake of the patient's well-being rather than gatekeep information to accelerate medical interviews. This is evidenced in extract 3.

Extract 3

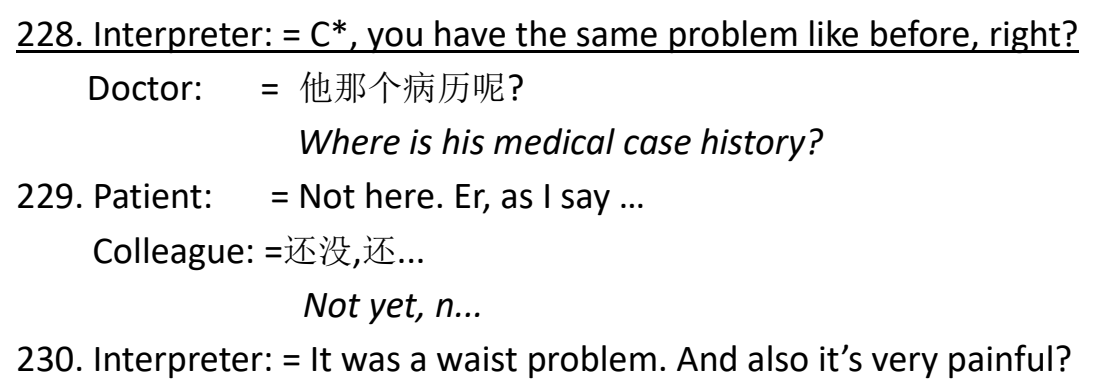


Zhang, W., \& Xu, C. (2021). Visibility of Chinese ad hoc medical interpreters through text ownership: A case study. Linguistica Antverpiensia, New Series: Themes in Translation Studies, 20, 136-158.

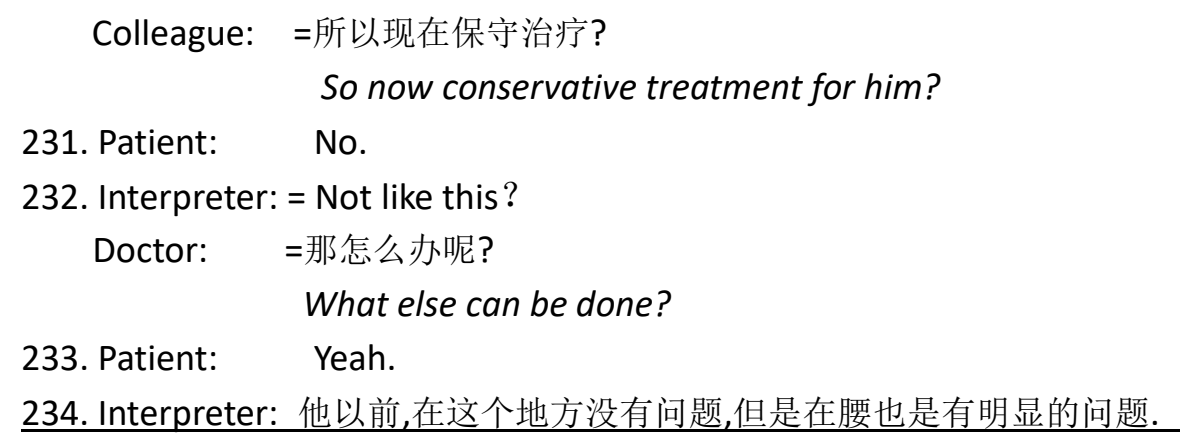

Previously he had no problem in this place, but he had a serious problem in his lower back.

235. Colleague: 那就是-

So that's-

236. Doctor: 那就是老腰了.

That's a long lower backache history.

237. Interpreter: 以后就是他这儿就好了,这儿就好了.

Later he has no problem here, no problem here.

238. Patient: When I drive,

$=$ I drive too much. Maybe two hours.

239. Doctor: =这一次就是加重了.一个是这个长时间的坐,这个,而且经常带的东西比较多, 弯腰搬个东西什么的,你看他的块儿也很大.

This time the pain has aggregated. One reason is his sedentary lifestyle. Besides, he may often carry a lot of things, so he needs to bend down to move things (which may further aggravate his lower backache). See, he has big muscles.

240. Interpreter: 他以前就是开车开很长时间也有过腰的问题.

He used to drive for a very long time, and at that time he was already suffering from lower backache.

In this extract, two side conversations regarding the patient's medical history were taking place simultaneously, which led to overlapping turns (turns 228, 229, 230 and 232, as indicated by the "=" symbol). On the one hand, the doctor and the patient's Chinese colleague were discussing the patient's medical history while, on the other hand, the interpreter, acting as a co-diagnostician, was making some enquiries about the patient's medical history with reference to his lower back pain. By creating his own lines (underlined sections) to elicit more treatment-related information and report back to the physician, the interpreter became the author and helped facilitate the medical interview.

\subsubsection{Brokering comprehension}

Medical interviews often abound with terminology, one of the main language barriers in institutional talk (see also Pöllabauer, 2017). Meyer (2006) reported that ad hoc interpreters in such cases tend to "de-terminologise" specific terms by paraphrasing them in plain language (p. 21; cited from Pöllabauer, 2017). Pöllabauer (2017) called such a practice "ad hoc terminology management" (p. 134), whereas, according to Angelelli (2004a), this practice 
Zhang, W., \& Xu, C. (2021). Visibility of Chinese ad hoc medical interpreters through text ownership: A case study. Linguistica Antverpiensia, New Series: Themes in Translation Studies, 20, 136-158.

indicates the interpreter's active efforts to broker comprehension and balance the distribution of power between doctor and patient. In this study, we also found cases where the ad hoc interpreter took on the role of broker when the terminology proved difficult for the patient.

Extract 4

137. Doctor: ... 就是这个脚麻木吗?

Is this foot numb?

138. Interpreter: Is it numb at all?

139. Patient: Sorry?

140. Interpreter: Numb, in other word, you know what numb is? You can't feel. Can you feel?

141. Doctor: Ah, numb, numb.

142. Patient: What's numb?

143. Interpreter: Numb is you have no feeling.

144. Patient: Ah, numb. I have feeling.

145. Interpreter: 他有感觉, 不太麻木.

He has feeling, not feeling very numb.

In this case, the doctor first asked the patient to move his feet to check whether he felt numb due to his lower back pain. Speaking very limited English, the Mozambican patient experienced difficulty in understanding the term "numb", as indicated in turns 139 and 142. Upon seeing this, the interpreter stepped in by explaining in plain language the meaning of numb (turns 140 and 143), and equated numb to "no feeling" to help facilitate better understanding. By taking the initiative to author the text, he obtained the information the doctor asked for (turn 137) and therefore helped to facilitate the medical treatment.

\subsubsection{Summary of distribution of the four manifestations of text ownership}

As summarized in Table 3, overall, the ad hoc interpreters in all three cases exhibited a high degree of visibility by claiming either partial or total text ownership. In case 1 , the interpreter was the most visible participant, as manifested by his patient advocate and co-diagnostician roles. The interpreter in case 2 , a college student and a language partner of the patient, seemed to be more visible in her role as the patient's spokesperson, because in many cases she tended to replace the patient in answering the doctor's questions. The interpreters in case 3 also stepped in quite often, acting as the patient's advocate and a co-diagnostician. However, differently from colleague interpreters, they regarded their efforts as their responsibility as members of the hospital staff.

Their heterogeneous identities or social roles (company staff, student, hospital staff) aside, all of these ad hoc interpreters were essentially patient-oriented. Instead of translating word for word like animators, they were very active in creating their own lines to elicit, as much as they could, the information that was necessary for the medical consultations. Challenging Goffman's (1956) concept of the non-person, who is "present during the interaction but do not, in a sense, take on the role either of performer or of audience, nor do they pretend to be 
Zhang, W., \& Xu, C. (2021). Visibility of Chinese ad hoc medical interpreters through text ownership: A case study. Linguistica Antverpiensia, New Series: Themes in Translation Studies, 20, 136-158.

what they are not" (p. 95), these untrained interpreters were highly visible and active coparticipants and, sometimes, co-interlocutors (Ren, 2010), facilitating and (co-)constructing the triadic interactions.

Table 3. Distribution of four manifestations of text ownership (percentage)

\begin{tabular}{|l|l|l|l|l|}
\hline Category & Case 1 & Case 2 & Case 3 & \multicolumn{1}{|c|}{$\begin{array}{c}\text { Total proportion of } \\
\text { turns }\end{array}$} \\
\hline Replacing the interlocutor & $1.4 \%$ & $2.2 \%$ & $0 \%$ & $3.6 \%$ \\
\hline Expressing affect & $2.4 \%$ & $1.0 \%$ & $2.5 \%$ & $5.9 \%$ \\
\hline Exploring answers & $4.1 \%$ & $0.6 \%$ & $1.8 \%$ & $6.5 \%$ \\
\hline Brokering comprehension & $0.7 \%$ & $0 \%$ & $0.4 \%$ & $1.1 \%$ \\
\hline Total & $8.6 \%$ & $3.8 \%$ & $4.7 \%$ & $17.1 \%$ \\
\hline
\end{tabular}

\subsection{In between - visibility not explainable by text ownership}

Whereas Angelelli (2004a) summarized a number of strategies for claiming text ownership, there are other "strategies" that cannot be readily explained, such as interpreters' omissions of certain remarks made by primary interlocutors (i.e., doctor or patient), leading to "zero renditions" (Wadensjö, 1998, p. 108). The analysis of omissions demonstrates that ad hoc interpreters visibly intervened quite drastically in the process of content transfer, as exemplified in extract 5 where the doctor explicitly authorized the interpreter to do the translation while the interpreter failed to do so.

Extract 5

304.Doctor：然后呢你跟她说一下, 第一呢就是带着这个玩意, 然后呢如果过两天加重了做下 CT, 然后呢就是这四五天之内冷敷冷敷,四五天之后热敷热敷,跟她说, 回去之后 冷敷, 不要走路, 最关键是不要走路.

Then you tell her, first she should wear this stuff, and if the pain gets worse about two days later, she should come back to do the CT. In the first four to five days, she should apply a cold compress, and afterwards apply a hot compress. Tell her, apply a cold compress when she gets back, and do not walk. The most important thing is do not walk.

305. Interpreter: 嗯.

\section{((onomatopoeic sound that confirms previous statement))}

306. Friend 1: Don't walk, do you mean that? ((laughter)) Don't walk.

307. Doctor: Good luck for you.

Towards the end of the medical treatment in case 2, the doctor again stressed some important notes to the interpreter, which were expected to be translated on the spot (turn 304). However, the interpreter failed to respond to the doctor's request by making only an implied promise that she would tell the patient when they got back (underlined section). One possible reason for such an omission is that, at that moment the ad hoc interpreter may have discarded her 
Zhang, W., \& Xu, C. (2021). Visibility of Chinese ad hoc medical interpreters through text ownership: A case study. Linguistica Antverpiensia, New Series: Themes in Translation Studies, 20, 136-158.

identity as a temporary translator, and instead may have seen herself as a friend. This may also be confirmed by the following turns (not illustrated here) in which she joined the others in extending their gratitude to the doctor. It is highly likely that, as a friend, she did not feel the necessity to translate the doctor's advice immediately. Nonetheless, the interpreter's exercise of agency to make "zero renditions" (Wadensjö, 1998) in such cases may pose potential clinical risks, especially when the patient has not been adequately notified of proper medical advice by the doctor.

Omissions were found in all three cases (Table 4). From the transcriptions, we found that the majority of omissions were made when the doctor and the patient communicated directly with each other either in English or in Chinese, supported by certain body language. Nevertheless, in many cases, interpreters with heterogeneous identities make omissions for different reasons. Colleague interpreters may skip translations since they can deliver the message to the patient later when they are back home; hospital staff see no necessity in translating when the physician speaks to the patient directly in English. Regardless of the reasons, we concur with previous scholarship (e.g., Angelelli, 2004a; Prince, 1986) that omissions, deliberate or not, of the remarks made by primary interlocutors deprive doctor and the patient of the opportunity to communicate directly, and this may lead to clinical risks.

Table 4. Distribution of omissions (percentage)

\begin{tabular}{|l|l|l|l|l|l|}
\hline \multicolumn{2}{|l|}{ Type 5 } & Case 1 & \multicolumn{1}{|c|}{ Case 2 } & \multicolumn{1}{|c|}{ Case 3 } & $\begin{array}{c}\text { Total proportion of } \\
\text { turns }\end{array}$ \\
\hline \multirow{2}{*}{ Omissions } & of doctor's remarks & $0.8 \%$ & $2.3 \%$ & $1.4 \%$ & $4.5 \%$ \\
\cline { 2 - 6 } & of patient's remarks & $1.0 \%$ & $1.3 \%$ & $1.4 \%$ & $3.7 \%$ \\
\hline \multirow{2}{*}{ Total } & $1.8 \%$ & $3.6 \%$ & $2.8 \%$ & $8.2 \%$ \\
\hline
\end{tabular}

In addition to omissions, another visible role performance is constant small talk, or side conversations, between interpreter and doctor (and sometimes between interpreter and patient). Penn and Watermeyer (2012) defined a side conversation as "either interpreter- or patient- initiated aside which remain uninterpreted in the immediate interactional context" ( $p$. 392). In our study, side conversations were mostly initiated by the doctor or by the ad hoc interpreters (this role performed by hospital staff members). Some small talk is non-serious, aiming to "[frame] comfort levels" (Penn \& Watermeyer, p. 393) and ease the atmosphere, while some is diagnosis-related. Van de Mieroop (2016) pointed out: "[e]ven though the importance of small talk in institutional interactions has been extensively demonstrated in sociolinguistic studies, it has never been the object of analysis in interpreted interactions" ( $p$. 292).

The reason why small talk plays an important role in manifesting the interpreter's visibility is that it allows the interpreter "to do a variety of identity work far beyond the prescribed role of translator" (Van de Mieroop, 2016, p. 292). In other words, once interpreters are involved in small talk, their visibility is officially acknowledged by the primary interlocutors in the 
Zhang, W., \& Xu, C. (2021). Visibility of Chinese ad hoc medical interpreters through text ownership: A case study. Linguistica Antverpiensia, New Series: Themes in Translation Studies, 20, 136-158.

institutional interaction. However, owing to space limitations, we cannot offer to illustrate in detail how interpreters are constantly involved in these side conversations initiated by the doctor. Nevertheless, these side conversations, as argued by Penn and Watermeyer (2012), "also [yield] critical diagnostic and therapeutic information" (p. 391). Future work can be done on this aspect to reveal the visible roles of medical interpreters more fully.

\section{Discussion}

In this study, as the findings reported in section 4 show, manifestations of interpreters' visibility - those both explainable and not explainable by text ownership - were detected. These demonstrate the analytic power of text ownership in revealing and categorizing interpreters' active role performances. This study has demonstrated the agency of untrained ad hoc interpreters in (co-)constructing and facilitating medical interactions and balancing the distribution of power between doctor and patient in a Chinese medical context.

The nature of interpreters' heterogeneous identities also influences their specific roles. To be specific, the colleague interpreters (cases 1 and 2) demonstrated visibility by taking on the roles of a patient's spokesperson and patient advocate; in contrast, hospital-based interpreters (case 3) self-identify as institutional members (i.e., doctors) rather than translators, and for them medical service quality is of great concern. However, we caution that replacing patients in the information elicitation phase together with omissions of primary interlocutors' remarks, whether deliberate or due to carelessness or a lack of professionalism, may compromise direct doctor-patient communication and deprive patients of opportunities to be heard (see also Prince, 1986).

To account for the motivations behind ad hoc interpreters' highly visible roles, we turn to Angelelli's (2004a, p. 10) model of "the visible interpreter", which has been constructed on the basis of a number of theories: linguistic anthropology, sociological theories, theories in interpersonal relations and, importantly, Bourdieu's theory of social practice (1972/1977). Simply put, this model suggests that interpreters' participation is triggered by "an interplay of social factors and [...] constrained by the norms of the institution and the society in which the interaction occurs" (Angelelli, 2004a, p. 76). The idea behind this theory is that interpreting never happens "in a social vacuum"; rather, it takes place in a "social context where the interaction is embedded" (Angelelli, 2004a, p.10). Therefore, interpreters enter the interaction

with all of their deeply held views on power, status, solidarity, gender, age, race, ethnicity, nationality, social-economic status (SES), as well as the cultural norms and societal blueprints that encompass the encounter. (Angelelli, 2004a, p.10)

Actually, not only interpreters but also each party participating in the interaction brings with them their own social factors to the encounter. Translated to our case study, each participating agent (e.g., doctor, patient, ad hoc interpreters, patient's friends) in the medical consultation 
Zhang, W., \& Xu, C. (2021). Visibility of Chinese ad hoc medical interpreters through text ownership: A case study. Linguistica Antverpiensia, New Series: Themes in Translation Studies, 20, 136-158.

brings with them to the interaction their deeply held views on social factors and reacts to the situation in their specific manner.

These deeply held views on social factors, to Angelelli's (2004a) way of understanding, are closely related to the concept of "habitus" (Bourdieu, 1972/1977), that is, "the past, present, and future dispositions that each participant brings to the encounter" (Angelelli, 2004a, p. 27). This concept is particularly enlightening when interpreters of heterogeneous identities are under examination. In her own analysis, Angelelli (2004a, p. 97) reported a case in which the interpreter's (i.e., Vicente) training as a physician contributed to his habitus, which encouraged him to investigate answers, expand utterances and broker cultural references.

This sheds light on the role performances of the two hospital-based interpreters investigated in our study, who tend to express affect towards patients by offering additional medical advice or expanding on the doctor's questions to elicit more diagnosis-related information, as has been illustrated in the following interview data.

\section{Excerpt $1^{2}$}

During medical treatment, we have a set of norms. Sometimes the patient probably needs nonmedical means, such as taking more rest or drinking more water. In such cases when a doctor of superior rank fails to mention this, I will contribute my own lines. Other times, I will confirm with the doctor whether certain medicines or physiotherapies are needed in case we have missed something.

\section{Excerpt 2}

Since we are also doctors, we tend to regard ourselves more as doctors than as translators. What we do in this process (while translating) is, er, how to say, to explain to the patient more vividly so that they can easily understand. We don't really regard ourselves as an interpreter, that "I am a translator". We just translate the doctor's remarks to the patient and vice versa. In this process we also want to acquire the information that a doctor needs.

Excerpts 1 and 2 illustrate that hospital-based interpreters' training as resident doctors contributed to their habitus, which in turn constrained their behaviours. Specifically, as resident doctors, they have acquired and internalized a set of institutional norms, such as the situations under which medical or non-medical treatment should be provided, as their professional habitus. Influenced by these internalized norms, they have been exposed to and also been driven by their deeply held views on other social factors, such as solidarity and the distribution of power between patient and doctor. They contribute their own texts by offering additional advice or eliciting more diagnosis-related information for the sake of the patient's welfare instead of translating what the doctor has said in a neutral and impartial way (i.e., following professional norms for medical interpreting). In doing this, they exercised their agency and contributed their share of responsibility in discourse construction. 
Zhang, W., \& Xu, C. (2021). Visibility of Chinese ad hoc medical interpreters through text ownership: A case study. Linguistica Antverpiensia, New Series: Themes in Translation Studies, 20, 136-158.

Aside from the institutional norms and interpreters' professional habitus, other "social baggage" (Angelelli, 2004a) also exerts an influence on interpreters' translational behaviour. This social baggage can take the form of social and cultural norms, values and beliefs acquired and internalized in the socialization of one's "growth, family education, school education, work and interaction" (Wang, 2011, p. 7). In our research, small talk between hospital-based interpreters and the patient manifested the role of interpreters as active discourse contributors and co-constructors, especially in showing empathy (Merlini, 2015; Merlini \& Gatti, 2015) or emotional support (Hsieh \& Hong, 2010) towards patients during small talk, as evidenced in excerpt 3:

\section{Excerpt 3}

I think this (offering their own suggestions) is a kind of humanistic care. ... The doctor that I interpreted for is, how to say, very easy-going. Patients have to go through a lot of procedures during medical treatment, such as doing an X-ray. So during this waiting time, we may engage in small talk with them to lighten the atmosphere. Sometimes the doctor will ask patients about their household affairs to ease their tension, and also to remind them of something they may have neglected when they got injured or fell ill. Through chit-chat, patients may become more relaxed.

This excerpt reveals how hospital-based interpreters shouldered their social responsibility as "socialized persons" (Simeoni, 1998). This interaction between agency and responsibility, especially in showing empathy and solidarity towards the patient, has also been amply demonstrated in Angelelli (2004a) through the lens of linguistic anthropology, which allows us to see the interplay between linguistic message and social context. The humanistic care expressed by hospital-based interpreters is precisely the manifestation of the social value they have acquired and internalized in the process of socialization.

\section{Concluding remarks}

The question of the (in)visibility of medical interpreters is essentially linked to the question of the role(s) medical interpreters are expected to play and also the intensity of their involvement in interpreter-mediated interaction (see also Cox, 2015). The traditional conduit model stipulates that an invisible interpreter is "a conduit transmitting messages between parties reliably and without distortion" (Dysart-Gale, 2005, p. 92). On the basis of this model, interpreting is treated as "a merely linguistic issue" (Cox, 2015, p. 164) isolated from the context in which it is embedded. However, as has been amply discussed in Angelelli (2004a) and other studies (e.g., Wang, 2011), interpreters as socialized persons carry with them their social baggage acquired during socialization, such as "ethnicity, level of education, and socioeconomic status" (Angelelli, 2004a, p. 77). A conduit model, therefore, does not fit interpretermediated medical interaction, which involves far more social and cultural factors than simple linguistic issues. 
Zhang, W., \& Xu, C. (2021). Visibility of Chinese ad hoc medical interpreters through text ownership: A case study. Linguistica Antverpiensia, New Series: Themes in Translation Studies, 20, 136-158.

The three ad hoc interpreters investigated in this research all displayed visible roles (e.g., patient's spokesperson, patient advocate, co-diagnostician) other than that of a mere translation machine. However, discourse analysis and follow-up interviews showed that these "chance" interpreters do not identify themselves as translators per se. Their social baggage (Angelelli, 2004a) or habitus (Bourdieu, 1972/1977) shaped during their socialization facilitates their visible role performances: colleague interpreters aim to help out their friends by acting as a temporary interpreter to overcome language barriers encountered during a doctorpatient consultation, while hospital-based staff interpret in conformity with the institutional norms they have been exposed to. They all try to facilitate medical treatment, even though they have not received any proper training for medical interpreting. In addition, their excessive visibility may sometimes turn out to be counter-productive (Zhan \& Zeng, 2017), especially when opportunities for direct doctor-patient communication are compromised.

This study contributes to the limited studies on medical interpreting in China. It offers a glimpse of the under-developed status of community interpreting in China (see also Su, 2009) compared to that in European countries. One important reason for this situation, as has been briefly mentioned above, is the lack of professional medical interpreting services because hospital staff are often bilingual and can communicate directly with patients in English. This also accounts for a major limitation in our study: the inclusion of only three cases. Given the limited number of cases investigated, our findings in this study cannot be generalized. However, by analyzing the actual role performances of ad hoc untrained interpreters, we aim to draw researchers' and healthcare providers' attention to the status quo of language services in China and also to the potential clinical risks of non-professional interpreting. We hope that these results contribute to the recognition of professional medical interpreting as a basic right for patients who cannot speak Chinese and that they open the way to professionalizing and standardizing medical interpreting. 
Zhang, W., \& Xu, C. (2021). Visibility of Chinese ad hoc medical interpreters through text ownership: A case study. Linguistica Antverpiensia, New Series: Themes in Translation Studies, 20, 136-158.

\section{Appendix: Transcription rules (adapted from Wadensjö 1998, p. 102)}

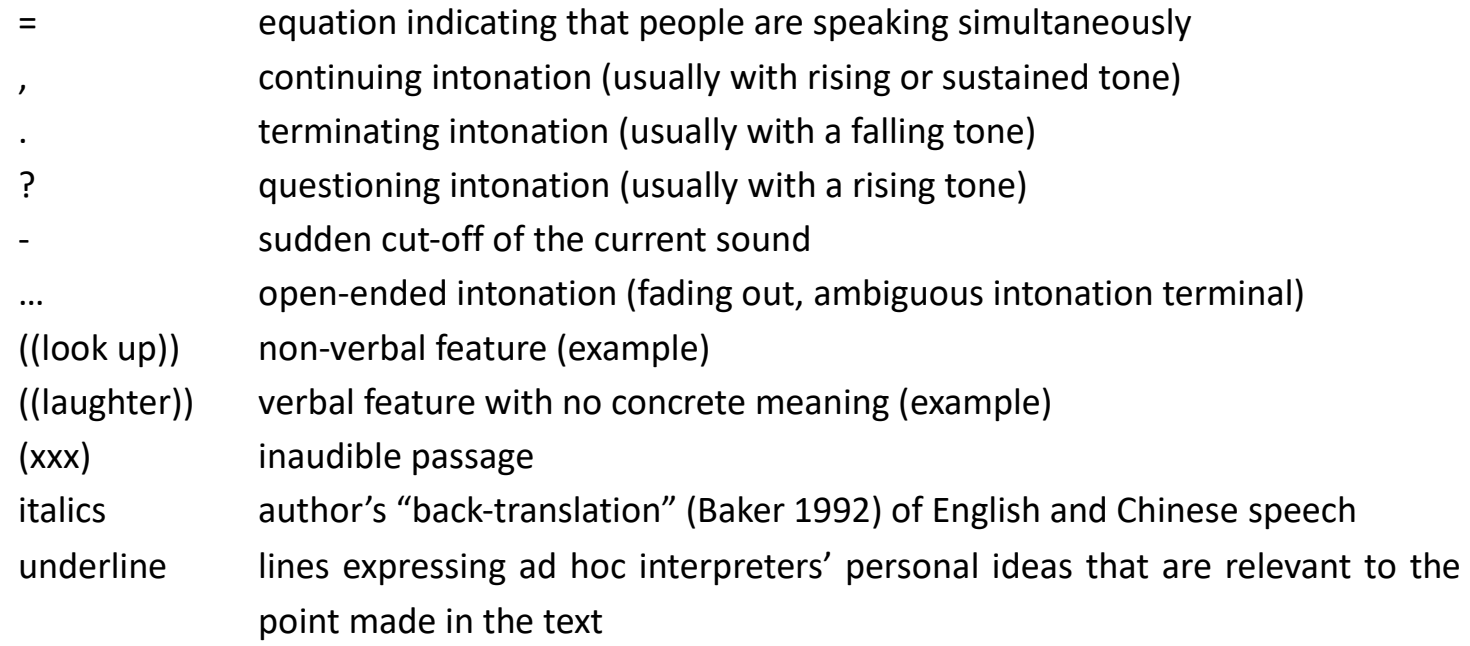

\section{Acknowledgement}

This work was supported by the National Social Science Fund of China (Grant ID: 18AYY013). 
Zhang, W., \& Xu, C. (2021). Visibility of Chinese ad hoc medical interpreters through text ownership: A case study. Linguistica Antverpiensia, New Series: Themes in Translation Studies, 20, 136-158.

\section{References}

Angelelli, C. V. (2004a). Medical interpreting and cross-cultural communication. Cambridge University Press. https://doi.org/10.1017/CBO9780511486616

Angelelli, C. V. (2004b). Revisiting the interpreter's role: A study of conference, court, and medical interpreters in Canada, Mexico, and the United States. John Benjamins. https://doi.org/10. $\underline{1075 / \text { btl. } 55}$

Baraldi, C., \& Gavioli, L. (2017). Intercultural mediation and "(non)professional" interpreting in Italian healthcare institutions. In R. Antonini, L. Cirillo, L. Rossato, \& I. Torresi (Eds.), Non-professional interpreting and translation (pp. 83-106). John Benjamins. https://doi.org/10.1075/btl.129.05 $\underline{\text { bar }}$

Bolden, G. B. (2000). Toward understanding practices of medical interpreting: Interpreters' involvement in history taking. Discourse Studies, 2(4), 387-419. https://doi.org/10.1177/14614456000020 $\underline{04001}$

Bourdieu, P. (1977). Outline of a theory of practice. R. Nice. (Translated into English. Original Esquisse d'une théorie de la pratique, précédé de trois études d'ethnologie kabyle, 1972). Cambridge: Cambridge University Press. https://doi.org/10.1017/CBO9780511812507

Bischoff, A., \& Hudelson, P. (2010). Access to healthcare interpreter services: Where are we and where do we need to go? International Journal of Environmental Research and Public Health, 7(7), 2838-2844. https://doi.org/10.3390/ijerph7072838

Bührig, K., \& Meyer, B. (2004). Ad hoc-interpreting and the achievement of communicative purposes in doctor-patient-communication. In J. House \& J. Rehbein (Eds.), Multilingual communication (pp. 43-62). John Benjamins. https://doi.org/10.1075/hsm.3.04buh

California Healthcare Interpreters Association. (2002). California standards for healthcare interpreters: Ethical principles, protocols, and guidance on roles and intervention. California Endowment.

Clifford, A. (2005). Healthcare interpreting and informed consent: What is the interpreter's role in treatment decision-making? TTR: Traduction, Terminologie, Rédactio, 18(2), 225-247. https:// doi.org/10.7202/015772ar

Cox, A. (2015). Do you get the message?: Defining the interpreter's role in medical interpreting in Belgium. MonTI. Monografías De Traducción E Interpretación, 161-184. https://doi.org/10. 6035/MonTI.2015.ne2.6

Crezee, I. H. M., \& Ng, E. N. S. (2016). Introduction to healthcare for Chinese-speaking interpreters and translators. John Benjamins. https://doi.org/10.1075/z.202

Davidson, B. (2000). The interpreter as institutional gatekeeper: The social linguistic role of interpreters in Spanish-English medical discourse. Journal of Sociolinguistics, 4(3), 379-405. https://doi. org/10.1111/1467-9481.00121

Davidson, B. (2001). Questions in cross-linguistic medical encounters: The role of the hospital interpreter. Anthropological Quarterly, 74(4), 170-178. https://doi.org/10.1353/anq.2001.00 $\underline{35}$

Dysart-Gale, D. (2005). Communication models, professionalization, and the work of medical interpreters. Health Communication, 17(1), 91-103. https://doi.org/10.1207/s15327027hc170 
Zhang, W., \& Xu, C. (2021). Visibility of Chinese ad hoc medical interpreters through text ownership: A case study. Linguistica Antverpiensia, New Series: Themes in Translation Studies, 20, 136-158.

\section{$\underline{16}$}

Gerrish, K., Chau, R., Sobowale, A., \& Birks, E. (2004). Bridging the language barrier: The use of interpreters in primary care nursing. Health \& Social Care in the Community, 12(5), 407-413. https://doi.org/10.1111/j.1365-2524.2004.00510.x

Goffman, E. (1956). The presentation of self in everyday life. University of Edinburgh.

Goffman, E. (1981). Forms of talk. University of Pennsylvania Press.

Herrera, L. (2008). The unsolved problem, medical interpretation in Japan. Kokusai Hoken Tryo (Journal of International Health), 23(1), 13-14. https://doi.org/10.11197/jaih.23.13

Hsieh, E. (2006). Understanding medical interpreters: Reconceptualizing bilingual health communication. Health Communication, 20(2), 177-186. https://doi.org/10.1207/s15327027 $\underline{\text { hc2002 } 9}$

Hsieh, E. (2007). Interpreters as co-diagnosticians: Overlapping roles and services between providers and interpreters. Social Science and Medicine, 64, 924-937. https://doi.org/10.1016/j.socsci med.2006.10.015

Hsieh, E. (2008). "I'm not a robot!": Interpreters' views of their roles in health care settings. Qualitative Health Research, 18(10), 1367-1383. https://doi.org/10.1177/1049732308323840

Hsieh, E., \& Hong, S. J. (2010). Not all are desired: Providers' views on interpreters' emotional support for patients. Patient Education Counseling, 81(2), 192-197. https://doi.org/10.1016/i.pec.2010. $\underline{04.004}$

Kaufert, J. M., \& Putsch, R. W. (1997). Communication through interpreters in healthcare: Ethical dilemmas arising from differences in class, culture, language, and power. The Journal of Clinical Ethics, 8(1), 71-87. http://www.tararogersinterpreter.com/uploads/1/0/3/7/103709790/kau fert 029 communication through interpreters in healthcare.pdf

Knapp-Potthoff, A., \& Knapp, K. (1986). Interweaving two discourses: The difficult task of the nonprofessional interpreter. In J. House \& S. Blum-Kulka (Eds.), Interlingual and intercultural communication: Discourse and cognition in translation and second language acquisition studies (pp. 151-168). Gunter Narr.

Larrison, C. R., Velez-Ortiz, D., Hernandez, P. M., Piedra, L. M., \& Goldberg, A. (2010). Brokering language and culture: Can ad hoc interpreters fill the language service gap at community health centers? Social Work in Public Health, 25(3-4), 387-407. https://doi.org/10.1080/193719109 $\underline{03241009}$

Lee, K. C., Winickoff, J. P., Kim, M. K., Campbell, E. G., Betancourt, J. R., Park, E. R., Maina, A. W., \& Weissman, J. S. (2006). Resident physicians' use of professional and nonprofessional interpreters: A national survey. Jama, 296(9), 1049-1054. https://doi:10.1001/iama.296.9.10 $\underline{50}$

Massachusetts Medical Interpreters Association and Education Development Center, I.M. (1995). Medical interpreting standards of practice. Massachusetts Medical Interpreters Association.

Merlini, R. (2015). Empathy: A 'zone of uncertainty' in mediated healthcare practice. Cultus: The Journal of Intercultural Mediation and Communication, 8, 27-49.

Merlini, R., \& Gatti, M. (2015). Empathy in healthcare interpreting: Going beyond the notion of role. The Interpreters' Newsletter, 20, 139-160.

Meyer, B. (2006). Aufklärungsgespräche mit Dolmetscherbeteiligung: Fachexterne Fachkommunikation 
Zhang, W., \& Xu, C. (2021). Visibility of Chinese ad hoc medical interpreters through text ownership: A case study. Linguistica Antverpiensia, New Series: Themes in Translation Studies, 20, 136-158.

im mehrsprachigen Kontext. Fachsprache (1990), 28(1-2), 15-28.

Nimmon, L., \& Stenfors-Hayes, T. (2016). The "Handling" of power in the physician-patient encounter: perceptions from experienced physicians. BMC Medical Education, 16(1), 1-9. https://doi.org/ 10.1186/s12909-016-0634-0

Penn, C., \& Watermeyer, J. (2012). When asides become central: Small talk and big talk in interpreted health interactions. Patient Education and Counseling, 88(3), 391-398. https://doi.org/10.10 16/i.pec.2012.06.016

Pöllabauer, S. (2017). Issues of terminology in public service interpreting. In R. Antonini, L. Cirillo, L. Rossato, \& I. Torresi (Eds.). Non-professional interpreting and translation (pp. 131-155). John Benjamins. https://doi.org/10.1075/btl.129.07pol

Prince, C. D. (1986). Hablando con el doctor: Communication problems between doctors and their Spanish-speaking patients [Doctoral dissertation]. ProQuest Dissertations and Theses database.

Reddy, M. (1979). The conduit metaphor: A case of frame conflict in our language about language. Cambridge University Press.

Ren, W. (2010). The liaison interpreter's subjectivity consciousness. Foreign Language Teaching and Research Press.

Roy, C. B. (2000). Interpreting as a discourse process. Oxford University Press.

Simeoni, D. (1998). The pivotal status of the translator's habitus. Target, 10(1), 1-39. https://doi.org/ 10.1075/target.10.1.02sim

Su, W. (2009). Community interpreting in China. Shanghai Journal of Translators, 4, 42-45.

Tebble, H. (1998). Medical interpreting: Improving communication with your patients. Language Australia.

Ticca, A. C. (2017). More than mere translators: The identities of lay interpreters in medical consultations. In R. Antonini, L. Cirillo, L. Rossato, \& I. Torresi (Eds.). Non-professional interpreting and translation (pp. 107-130). John Benjamins. https://doi.org/10.1075/btl.129. $\underline{\text { 06tic }}$

Valero-Garcés, C. (2005). Doctor-patient consultations in dyadic and triadic exchanges. Interpreting, 7(2), 193-210. https://doi.org/10.1075/intp.7.2.04val

Van De Mieroop, D. (2016). Small talk in interpreted interactions in a medical setting. Language and Intercultural Communication, 16(2), 292-312. https://doi.org/10.1080/14708477.2015.11174 $\underline{83}$

Wadensjö, C. (1998). Interpreting as interaction: On dialogue interpreting in immigration hearings and medical encounters. Addison Wesley Longman.

Wang, Y. C. (2011). Translation through a Bourdieusian sociological lens. Chinese Translators Journal, 1, 5-13.

Zhan, C., \& Yan, M. B. (2013). Status quo, problems, and future development of medical interpreting in China: A study of medical interpreting. Journal of Guangdong University of Foreign Studies, 3, 47-50.

Zhan, C., \& Zeng, L. S. (2017). Chinese medical interpreters' visibility through text ownership: An empirical study on interpreted dialogues at a hospital in Guangzhou. Interpreting, 19(1), 98118. https://doi.org/10.1075/intp.19.1.05zha 
Zhang, W., \& Xu, C. (2021). Visibility of Chinese ad hoc medical interpreters through text ownership: A case study. Linguistica Antverpiensia, New Series: Themes in Translation Studies, 20, 136-158.

1 In this article, the italics in Extracts 1 to 6 are literal translations of the Chinese remarks introduced by the authors.

2 Excerpts 1 to 3 are literal translations of the interviewee's remarks introduced by the authors. 